\title{
Survival analysis in patients with metastatic spinal disease: the influence of surgery, histology, clinical and neurologic status
}

\author{
Análise de sobrevida em pacientes com doença metastática espinhal: influência da \\ cirurgia, histologia, status clínico e neurológico \\ Matheus Fernandes de Oliveira, Jose Marcus Rotta, Ricardo Vieira Botelho
}

\begin{abstract}
Spine is the most common site for skeletal metastasis in patients with malignancy. Vertebral involvement quantification, neurological status, general health status and primary tumor histology are factors to set surgical planning and therapeutic targets. We evaluated the impact of general clinical and neurological status, histologic type and surgery in survival. Method: The study sample consisted of consecutive patients admitted from July 2010 to January 2013 for treatment. Results: Sixty eight patients were evaluated. 23 were female and 45 were male. Main primary neoplasic sites were: breast, prostate, lung/pleura and linfoproliferative. Thirty three out of 68 received surgical treatment, 2 received percutaneous biopsy and 33 had nonsurgical treatment. Survival: Log Rank curves revealed no statistical significant difference according to histological type, surgical approach and Frankel Score. Karnofsky Score was statistically different. Conclusion: Histological type and clinical status were statistically associated with life expectancy in vertebral metastatic disease.
\end{abstract}

Keywords: neoplasm metastasis, spinal diseases, prognosis.

RESUMO

A coluna vertebral é o sítio mais comum de metastases ósseas. A quantificação do acometimento vertebral, o status neurológico, status clínico e histologia do tumor primário são fatores importantes para planejamento cirúrgico e metas terapêuticas. Nós avaliamos o impacto do status clinico geral e neurológico, tipo histológico e cirurgia na sobrevida de pacientes com metástases espinhais. Método: A amostra consistiu de pacientes consecutivamente admitidos de Julho de 2010 a Janeiro de 2013. Resultados: Sessenta e oito pacientes foram avaliados. 23 eram mulheres e 45 eram homens. Os principais sítios primários foram mama, próstata, pulmão e linfoproliferativos. Trinta e três realizaram tratamento cirúrgico, 2 realizaram biópsia percutânea e 33 tiveram tratamento conservador e radioterapia. Conclusão: As curvas Log Rank não revelaram significância quanto à cirurgia e escore de Frankel, mas revelaram associação com Karnofsky e tipo histológico.

Palavras-chave: metástases, doenças espinhais, prognóstico.

The spine is the most common site for skeletal metastasis in patients with malignancy. Approximately half of all patients with an advanced malignancy have evidence of spinal involvement. Surgical treatment remains a source of debate, and prognostic factors need to be well established to allow an appropriate decision regarding treatment modalities ${ }^{1,2,3,4,5}$.

Vertebral involvement in such patients is associated with worse morbidity and mortality rates, impairing prognosis. Quantification of vertebral involvement, vertebral canal invasion, neurological status, general health status, and malignancy prognosis determined by primary tumor histology are paramount factors for surgical planning and definition of therapeutic targets ${ }^{6,7,8,9,10}$.

We conducted a survival analysis in a sample of patients with metastatic spinal disease to determine factors associated with survival.

\section{METHOD}

The study sample consisted of patients with vertebral metastases consecutively admitted from July 2010 to January

Hospital do Servidor Público Estadual de São Paulo, Departamento de Neurocirurgia, Sao Paulo SP, Brazil.

Correspondence: Matheus Fernandes de Oliveira; Rua Estado de Israel, 70 / ap. 51, Vila Clementino; 04022-002 São Paulo SP, Brasil; E-mail: mafernoliv@yahoo.com.br Conflict of interest: There is no conflict of interest to declare.

Received 29 September 2014; Received in final form 21 November 2014; Accepted 11 December 2014. 
2013 (30 months) at Hospital do Servidor Público Estadual de São Paulo (HSPE).

The project was approved by the HSPE Research Ethics Committee.

The factors of interest potentially related to survival were histological cancer type, neurological status (represented by the Frankel grade), performance status (as determined by the Karnofsky scale), and treatment strategy. The duration of follow-up ranged from 1 to 64 months, with a mean follow-up of 13.8 months.

\section{Statistics}

Parametric numerical data were expressed as mean \pm standard deviation, and nonparametric data, as median and percentages.

Data distribution was evaluated by the Kolmogorov-Smirnov test. Student's t-test was used for the paired and unpaired groups as appropriate. Kaplan-Meier estimates were used for wrank tests were used to compare Kaplan-Meier curves. The significance level was established as $\mathrm{p}<0.05$. All analyses were performed in the SPSS 20.0 software package.

\section{RESULTS}

\section{Sample data}

Sixty-eight consecutively enrolled patients with spinal metastasis, 23 female and 45 male, were evaluated. The mean age was $60.52 \pm 11.69$ years for women and $63.12 \pm 10.28$ years for men. There was no statistically significant difference in age between the two groups ( $\mathrm{p}>0.05$ ).

Of the 68 patients, only two were asymptomatic at initial presentation, both of whom were referred from the oncology department after an active search for metastasis. Twenty-one patients presented with spinal pain, 23 with neurological deficits, and 22 with both pain and neurological deficit.

Neurologically, six patients presented with complete deficit (Frankel grade A), three with Frankel grade B, 25 with Frankel grade C, 15 with Frankel grade D, and 19 were neurologically intact (Frankel grade E).

The Karnofsky score (KS) ranged from 30 to 100. Three patients (5\%) presented with a $\mathrm{KS}$ of 30 , seven with $\mathrm{KS}=40$, 13 patients with $\mathrm{KS}=50,23$ patients with $\mathrm{KS}=60$, eight patients with $\mathrm{KS}=70$, seven patients with $\mathrm{KS}=80$, six patients with $\mathrm{KS}=90$, and one patient with a score of 100 .

Spinal metastases were located in the thoracic spine in $79 \%$ of cases, in the lumbar spine in $42 \%$, in the cervical spine in $16 \%$, and in the sacral spine in $10 \%$ of cases.

The main primary sites of neoplasia were: breast $(n=18)$; prostate ( $\mathrm{n}=16)$; lung/pleura $(\mathrm{n}=11)$; non-Hodgkin lymphoma $(n=8)$; multiple myeloma $(n=5)$; colon $(n=3)$; and kidney $(n=2)$. Five other patients had other primary cancers (thyroid, larynx, biliary, gallbladder, and testicular cancer).

Thirty-three of the 68 patients (48.5\%) underwent surgical intervention (23 posterior approaches, one combined anterior and posterior, and one anterior alone), and two underwent percutaneous biopsy. The reasons for surgery were spinal cord decompression, vertebral instability, and biopsy. Patients without cord compression, neurological deficit, or vertebral instability and with known primary cancer $(\mathrm{n}=33)$ were treated in accordance with their specific tumor type and with radiotherapy (RT).

Surgical approach was planned according to spinal cord compression pattern and spinal instability. The majority of patients were submitted only to laminectomy and transpedicular decompression, without instrumentation, due to ongoing spinal cord compression syndrome and risk for evolution. In those patients with mainly anterior compression and/or higher instability, an anterior or combined approach was performed.

\section{Survival}

At the end of evaluation (January 2013 - 30 months), 57.3\% of patients had died (39 patients). Among those who died, the median survival was 20 months from diagnosis of primary disease and 7 months from diagnosis of spinal disease.

\section{Breast cancer}

Of the 18 patients with breast cancer, 12 (66\%) died before last follow-up. The median survival among patients who died was 28 months from diagnosis of primary disease and 10.5 months from diagnosis of spinal metastasis.

\section{Prostate cancer}

Of the 16 patients with prostate cancer, $12(75 \%)$ had died by the end of evaluation. The median survival among patients who died was 27 months from diagnosis of primary disease and 5.5 months from diagnosis of spinal metastasis.

\section{Lung/pleural cancer}

Of the 11 patients with lung/pleural cancer, seven (63\%) were dead by the end of evaluation. The median survival among patients who died was 12.5 months from diagnosis of primary disease and 4 months from diagnosis of spinal metastasis. The median survival among patients still alive at final evaluation was 69 months from diagnosis of primary disease and 5 months from diagnosis of spinal metastasis.

\section{Lymphoproliferative neoplasms Lymphomas}

Of the eight patients with non-Hodgkin lymphoma, two (25\%) had died by the end of evaluation, and six (75\%) were alive. The median survival among patients who died was 58.5 months from diagnosis of primary disease and 11 months from diagnosis of spinal metastasis. 


\section{Myeloma}

Of the five patients with multiple myeloma, one (20\%) was dead by the end of evaluation, and four ( $80 \%$ ) were alive. The median survival in the patient who died was 1 month from diagnosis of primary disease and 1 month from diagnosis of spinal metastasis. The median survival among stillliving patients was 46 months from diagnosis of primary disease and 2 months from diagnosis of spinal metastasis.

\section{Other primary sites}

Other histological cancer types were scarce in this sample, and so could not be pooled for analysis. Three patients had colon cancer, with a mortality rate of $33 \%$ during evaluation. Median survival in the patient who died was 115 months from diagnosis of primary disease and 1 month from diagnosis of spinal metastasis. The median survival among still-living patients was 48 months from diagnosis of primary disease and 18 months from diagnosis of spinal metastasis. Two patients had kidney cancer, with $100 \%$ mortality and a median survival of 15 months from diagnosis of primary disease and 11 months from diagnosis of spinal metastasis. One patient had biliary cancer and was still alive at final evaluation, with a survival time of 82 months from diagnosis of primary disease and 24 months from diagnosis of spinal metastasis. One patient had gallbladder cancer and was dead by final evaluation, with a survival time of 22 months from diagnosis of primary disease and 7 months from diagnosis of spinal metastasis. One patient had laryngeal cancer and also died before final evaluation, with a survival time of 10 months from diagnosis of primary disease and 7 months from diagnosis of spinal metastasis. One patient had Hürthle cell carcinoma of the thyroid and was alive at final

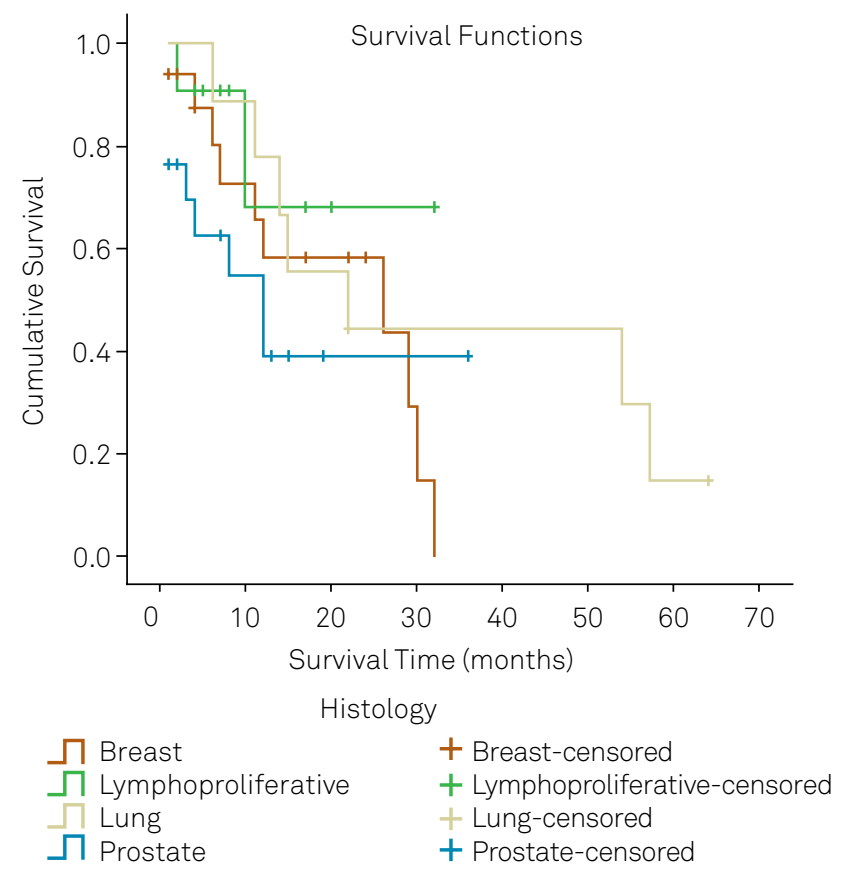

Figure 1. Survival by primary cancer site. evaluation, with a survival time of 2 months from diagnosis of primary disease and 2 months from diagnosis of spinal metastasis. Finally, one patient has seminomatous and non-seminomatous testicular cancer and had died by final evaluation, with a survival time of 8 months from diagnosis of primary disease and 8 months from diagnosis of spinal metastasis.

\section{Survival comparison (Figure 1)}

The log-rank curves of different histological cancer types are shown below. Survival was longer for lymphoproliferative cancers than for other types $(\mathrm{p}<0.001)$.

\section{Karnofsky score (Figure 2)}

We divided patients" Karnofsky scores into three groups for analysis: 10-40 (Group A), 40-70 (Group B), and > 70 (Group C). The median survival after spinal metastasis diagnosis was 4.5 months in Group A, 8.2 months in Group B, and 11.7 months in Group C. The difference was statistically significant $(p=0.016)$.

\section{Frankel grade (Figure 3)}

When evaluating Frankel scale grades, median survival was 7.6 months among Frankel A patients; 7.9 months among Frankel B patients; 6.4 months among Frankel C patients; 8.4 months among Frankel D patients; and 8.8 months among Frankel E patients. The difference was not statistically significant $(p=0.769)$.

\section{Survival difference between surgically and conservatively treated patients (Figure 4)}

By the end of follow-up, 18 of 33 patients who underwent surgical treatment had died, as had 21 of 35 who were

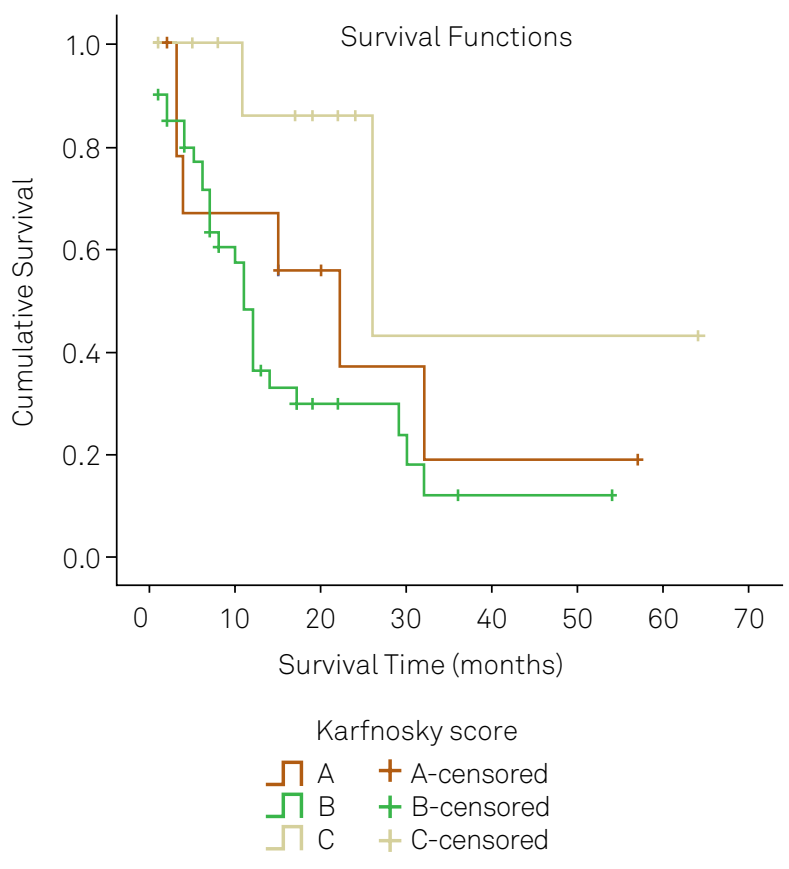

Figure 2. Survival according to Karnofsky Score. 


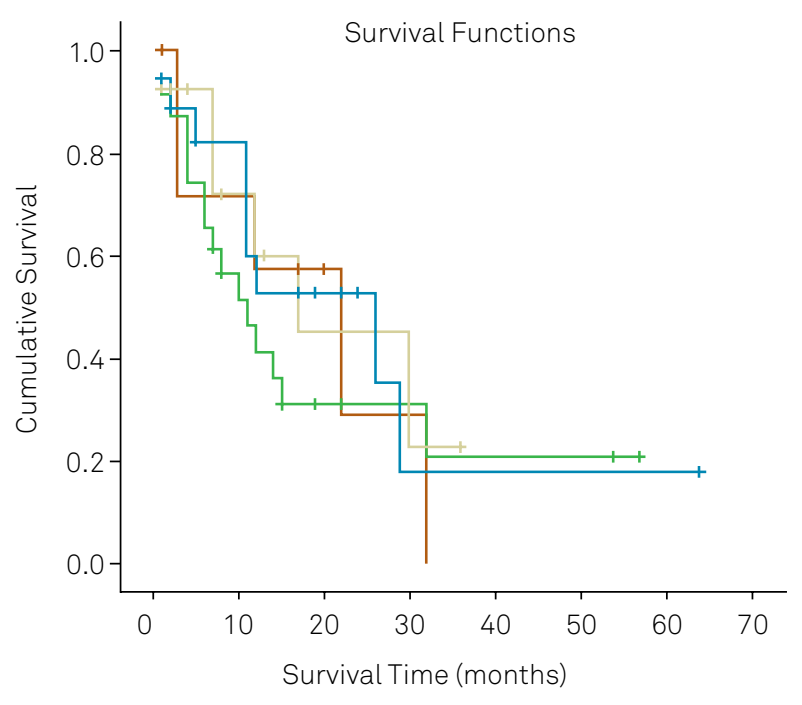

Neurological seficit

$\begin{array}{ll}\neg \text { Frankel A \& B } & \text { + Frankel A \& B-censored } \\ \square \text { Frankel C } & \text { + Frankel C-censored } \\ П \text { Frankel D } & + \text { Frankel D-censored } \\ \neg \text { Frankel E } & \text { + Frankel E-censored }\end{array}$

Figure 3. Survival according to Frankel Score.

treated conservatively. There was no difference in survival between the operative and conservative management groups $(\mathrm{p}=0.713)$.

\section{DISCUSSION}

A variety of surgical methods are available for the treatment of spinal metastases. Dorsal spinal decompression and stabilization are the most frequent surgical techniques used to treat metastatic disease of the thoracic and lumbar spine ${ }^{1,2,3,4,5,5,7,8,9,10}$. For patients with a solitary spinal metastasis without vertebral canal invasion and who are in good general health with a long life expectancy, tumor resection through en bloc spondylectomy/total vertebrectomy with primary stabilizing instrumentation has been suggested ${ }^{9,10,11,12,13}$. A recent paper reported that candidates for en bloc spondylectomy are not frequently encountered ${ }^{14,15,16}$.

In all scenarios, RT is a valuable tool to treat systemic disease and control emboligenic foci. Radiosurgery is also effective as either primary or adjunctive treatment of metastatic tumors of the spine. Preoperative embolization techniques can also be employed with the intention of controlling intraoperative bleeding ${ }^{5,6,17,18,19,20}$.

Prognosis can be predicted in to determine the best therapeutic approach. For this purpose, many systems have been proposed to guide decision-making, such as the Sioutos, Tomita, Van der Linden, Bauer, and Tokuhashi scores. In all cases, the main parameters used to estimate prognosis are preoperative ambulatory capacity, Karnofsky

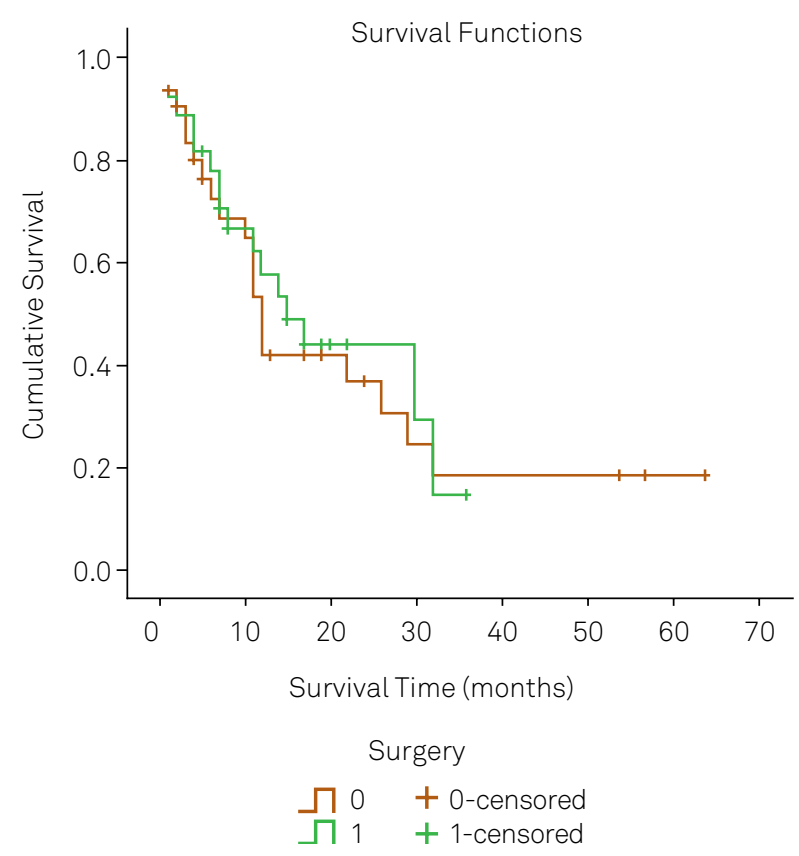

Figure 4. Survival according to treatment modality (conservative versus surgery).

performance status, RT, primary cancer type, presence of extraspinal metastasis, and number of spinal segments with metastasis. Additionally, pain on presentation and body mass index $25-30 \mathrm{~kg} / \mathrm{m}^{2}$ have been identified as predictors of poor outcome $\mathrm{e}^{21,22,23,24,25}$.

Our results confirm that the histologic diagnosis of spinal metastasis is an independent prognostic factor in the course of malignancy.

Although major advances in cancer treatment have been achieved in recent years, patients with vertebral metastasis still exhibit short survival. This suggests that vertebral involvement is indicative of aggressive cancer behavior.

We demonstrated an association between histological cancer type and survival, with lymphoproliferative neoplasms having the best survival rate. Additionally, Karnofsky score at presentation was also related to survival.

RT alone is usually advocated in patients with intact neurological status and patients with stable spines, who may be in good or poor clinical status. Surgery is generally indicated when neurological status and stability issues must be promptly addressed. In both situations, there is wide variation in prognostic factors. We found similar survival in patients treated with surgery plus RT and in those treated with RT alone s,6,26. $^{5}$.

Current evidence shows that surgery plays a decisive role in quality of life and survival rates, and final outcomes in patients receiving both surgery and RT are better than RT alone. These studies suggest that surgery can provide pain relief, neurologic improvement (in aspects such as ambulation), and aid recovery of general condition. Other reports 
have discussed the importance of patient age and revealed that, in patients over 60 years old, benefits may not be significant, especially due to the high risk of complications. In our sample, there was no difference in outcome between RT alone or RT + surgery ${ }^{5,6}$.

Surgery was not beneficial in terms of improving survival. Cancer type, aging, and advanced staging have greater influence on life expectancy than treatment type. Surgical complications, although not addressed in the present study, should not be neglected as a possible factor in lowering life expectancy.

It also bears stressing that preservation of ambulation, pain control, and functional independence are achieved more quickly after surgery than with conservative treatment. This may help patients face their disease in a more positive manner, which could entail better psychological status and superior treatment adherence.

Several limitations of this study must be addressed. First, our sample was recruited from a single tertiary referral center. Second, although sample size was robust, the number of patients in each subgroup should be greater. Then, there is an important question concerning linfoproliferative diseases. There is usually a discussion if vertebral lesions presented in these diseases are primary or metastatic. Once these diseases origin from hematopoietic elements and are present usually with diffuse vertebral and systemic involvement, we considered them as secondary lesions, similarly to other previous reports from literature ${ }^{3,13,16,21,22,23,24}$. Indeed, if linfoproliferative neoplasms were considered primary lesions in the present study, we would not reach statistical significant difference among survival rates of remaining histological types.

Finally, we did not apply in our sample any quality of life (QOL) assessment tool. We strongly believe QOL is very important in the context of such patients. However, our aim was to determine how much time they lived after metastasis diagnosis. As we confirmed, their survival is limited and surely is associated with poor QOL.

Current scientific evidence shows that advanced cancer staging is directly associated with poor prognosis. Patients with metastatic cancer are challenging to treat, because metastasis represents an advanced stage of the disease and, hence, is indicative of poor prognosis i,2,3,9,1,19. $^{1}$.

Knowledge of individual patient survival profiles has the potential to interfere with therapeutic targets and thus influence surgical and clinical treatment planning.

\section{References}

1. Akbar M, Ayache A, Eichler M, Klotz M, Wiedenhöfer B, Lehner B. [Management of spinal metastases, strategies and surgical indications]. Orthopade. 2012;41(8):632-9. German. http://dx.doi.org/10.1007/s00132-012-1910-2

2. Bilsky MH, Lis E, Raizer J, Lee H, Boland P. The diagnosis and treatment of metastatic spinal tumor.J Neurosurg. 1992;177(1):90-5.

3. Botelho RV, Oliveira MF, Rotta JM. Quantification of vertebral involvement in metastatic spinal disease. Open Orthop J. 2013;7(7):286-91. http://dx.doi.org/10.2174/1874325001307010286

4. Chataigner $\mathrm{H}$, Onimus M. Surgery in spinal metastasis without spinal cord compression: indications and strategy related to the risk of recurrence. Eur Spine J. 2000;9(6):523-7. http://dx.doi.org/10.1007/s005860000163

5. Chi JH, Gokaslan Z, McCormick P, Tibbs PA, Kryscio RJ, Patchell RA. Selecting treatment for patients with malignant epidural spinal cord compression-does age matter?: results from a randomized clinical trial. Spine. (Phila Pa 1976). 2009;34(5):431-5. http://dx.doi.org/10.1097/BRS.0b013e318193a25b

6. Delank KS, Wendtner C, Eich HT, Eysel PThe treatment of spinal metastases. Dtsch Arztebl Int. 2011;108(5):71-80. http://dx.doi.org/10.3238/arztebl.2011.0071

7. Demura S, Kawahara N, Murakami H, Abdel-Wanis ME, Kato S, Yoshioka K et al. Total en bloc spondylectomy for spinal metastases in thyroid carcinoma. J Neurosurg Spine. 2011;14(2):172-6. http://dx.doi.org/10.3171/2010.9.SPINE09878

8. Fehlings MG, David KS, Vialle L, Vialle E, Setzer M, Vrionis FD Decision making in the surgical treatment of cervical spine metastases. Spine (Phila Pa 1976). 2009;34(22 Suppl):S108-17. http://dx.doi.org/10.1097/BRS.0b013e3181bae1d2
9. Hessler C, Burkhardt T, Raimund F, Regelsberger J, Vettorazzi E, Madert J et al. Dynamics of neurological deficit after surgical decompression of symptomatic vertebral metastases. Spine. (Phila Pa 1976). 2009;34(6):566-71. http://dx.doi.org/10.1097/BRS.0b013e31819a825d

10. Itshayek E, Yamada J, Bilsky M, Schmidt M, Shaffrey C, Gerszten $P$ et al. Timing of surgery and radiotherapy in the management of metastatic spine disease: a systematic review. Int J Oncol. 2010;36(3):533-44. http://dx.doi.org/10.3892/ijo_00000527

11. Kilbride L, Cox M, Kennedy CM, Lee SH, Grant R. Metastatic spinal cord compression: a review of practice and care. J Clin Nurs. 2010;19(13-14):1767-83. http://dx.doi.org/10.1111/j.1365-2702.2010.03236.x

12. Lau D, Leach MR, La Marca F, Park P. Independent predictors of survival and the impact of repeat surgery in patients undergoing surgical treatment of spinal metastasis. J Neurosurg Spine. 2012;17(6):565-76. http://dx.doi.org/10.3171/2012.8.SPINE12449

13. Leithner A, Radl R, Gruber G, Hochegger M, Leithner K, Welkerling $H$ et al. Predictive value of seven preoperative prognostic scoring systems for spinal metastases. Eur Spine J. 2008;17(11):1488-95. http://dx.doi.org/10.1007/s00586-008-0763-1

14. Liang $T$, Wan $Y$, Zou X, Peng X, Liu S. Is surgery for spine metastasis reasonable in patients older than 60 years? Clin Orthop Relat Res. 2013;471(2):628-39. http://dx.doi.org/10.1007/s11999-012-2699-3

15. Murakami H, Kawahara N, Demura S, Kato S, Yoshioka K, Tomita K. Total en bloc spondylectomy for lung cancer metastasis to the spine. J Neurosurg Spine. 2010;13(4):414-7. http://dx.doi.org/10.3171/2010.4.SPINE09365

16. Oliveira MF, Barros BA, Rotta JM, Botelho RV. Tokuhashi Scoring System has limited applicability in the majority of patients with spinal cord compression secondary to vertebral metastasis. Arq Neuropsiquiatr. 2013;71(10):798-801. http://dx.doi.org/10.1590/0004-282X20130125 
17. Papastefanou S, Alpantaki K, Akra G, Katonis P. Predictive value of Tokuhashi and Tomita scores in patients with metastatic spine disease. Acta Orthop Traumatol Turc. 2012;46(1):50-6. http://dx.doi.org/10.3944/AOTT.2012.2645

18. Sciubba DM, Petteys RJ, Dekutoski MB, Fisher CG, Fehlings MG, Ondra SL et al. Diagnosis and management of metastatic spine disease: a review. J Neurosurg Spine. 2010;13(1):94-108. http://dx.doi.org/10.3171/2010.3.SPINE09202

19. Sheehan JP, Shaffrey CI, Schlesinger D, Williams BJ, Arlet V, Larner J. Radiosurgery in the treatment of spinal metastases: tumor control, survival, and quality of life after helical tomotherapy. Neurosurgery. 2009;65(6):1052-62. http://dx.doi.org/10.1227/01.NEU.0000359315.20268.73

20. Thomas KC, Nosyk B, Fisher CG, Dvorak M, Patchell RA, Regine WF et al. Cost-effectiveness of surgery plus radiotherapy versus radiotherapy alone for metastatic epidural spinal cord compression. Int J Radiat Oncol Biol Phys. 2006;66(4):1212-8. http://dx.doi.org/10.1016/j.ijrobp.2006.06.021

21. Tokuhashi Y, Matsuzaki H, Oda H, Oshima M, Ryu J. A revised scoring system for preoperative evaluation of metastatic spine tumor prognosis. Spine. 2001;30(19):2186-91. http://dx.doi.org/10.1097/01.brs.0000180401.06919.a5
22. Tokuhashi Y, Matsuzaki H, Toriyama S, Kawano H, Ohsaka S. Scoring system for the preoperative evaluation of metastatic spine tumor prognosis. Spine. 1990;15(11):1110-3. http://dx.doi.org/10.1097/00007632-199011010-00005

23. Tomita K, Kawahara N, Baba H, Tsuchiya H, Fujita T, Toribatake Y. Total en bloc spondylectomy. A new surgical technique for primary malignant vertebral tumors. Spine. 1997;22(3):324-33. http://dx.doi.org/10.1097/00007632-199702010-00018

24. Tomita K, Kawahara N, Kobayashi T, Yoshida A, Murakami H, Akamaru T. Surgical strategy for spinal metastases. Spine. 2001;26:298-306. http://dx.doi.org/10.1097/00007632-200102010-00016

25. Ulmar B, Huch K, Naumann U, Catalkaya S, Cakir B, Gerstner S et al. Evaluation of the Tokuhashi prognosis score and its modifications in 217 patients with vertebral metastases. Eur J Surg Oncol. 2007;33(7):914-9. http://dx.doi.org/10.1016/j.ejso.2006.11.018

26. Wibmer C, Leithner A, Hofmann G, Clar H, Kapitan M, Berghold A et al. Survival analysis of 254 patients after manifestation of spinal metastases: evaluation of seven preoperative scoring systems. Spine. 2011;36(23):1977-86. http://dx.doi.org/10.1097/BRS.0b013e3182011f84 